\title{
Deposit layer formation during skim milk dead-end filtration with ceramic hollow fiber membranes using magnetic resonance imaging
}

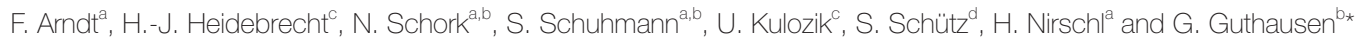

${ }^{a}$ Karlsruhe Institute of Technology, Institute of Mechanical Process Engineering and Mechanics and Pro ${ }^{2}$ MR, Straße am Forum 8 , 76131 Karlsruhe

${ }^{\mathrm{b}}$ Karlsruhe Institute of Technology, Pro ${ }^{2}$ NMR IBG-4 and MVM, Adenauerring 20b, 76131 Karlsruhe,

Corresponding Author: gisela.guthausen@kit.edu

${ }^{\mathrm{c}}$ TU München, Chair for Food and Bioprocess Engineering, Weihenstephaner Berg 1, 85354 Freising

${ }^{\mathrm{d}}$ MANN+HUMMEL GmbH, Schlieffenstraße 42, 71636 Ludwigsburg

A dead-end filtration process of skim milk with ceramic hollow fiber membranes was investigated using in situ Magnetic Resonance Imaging. Special emphasis was put on contrast optimization exploiting water relaxation times being sensitive to casein concentration in the formed deposit layer.

\section{Introduction}

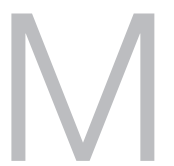

embrane filtration is known to be a major process in liquid food processing. The main applications of membranes in this field are in dairy, followed by beverage industry. ${ }^{1}$ An important application of membrane filtration processes in the dairy industry is the separation of casein micelles and whey proteins from milk by means of microfiltration. ${ }^{2}$ The resulting protein fractions are in their native states and have different nutritive and techno-functional properties. Hence, they are added to a wide range of food products. The challenge during the filtration is to completely retain casein micelles with a diameter between 50 and $400 \mathrm{~nm}\left(d_{50,3}=180 \mathrm{~nm}\right)$ while maximizing the permeation of whey proteins with $2-4 \mathrm{~nm}\left(d_{50,3}=3 \mathrm{~nm}\right)$. Although the pores of ordinary microfiltration membranes are by far bigger than whey proteins, the permeation is not $100 \%$ but only around $50 \%$ so far. This is mainly due to the casein micelles, which are retained and form a deposit layer that acts as a secondary layer on the membrane's surface. The consequence is a reduced permeate flux and protein permeation with increasing filtration time. ${ }^{3}$

Typically, the filtration flux is used to characterize the filtration performance. However, by using e.g. resistance in series models, only global filtration resistances for pore blocking and cake layer formation phenomena are obtained. ${ }^{4,5}$ These models enable the study of fouling phenomena. Nevertheless, they do not take into account, that the transmembrane pressure (TMP) decreases along the membrane due to friction forces in crossflow filtration processes which lead to an axial dependence of the filtration flux and permeation characteristics. ${ }^{2,6}$ Studies dealing with the length dependence of flux and deposit layer formation show diverging results. Gernedel $(1980)^{7}$ justified the declining flux along the membrane with the axial transportation of already deposited material towards the outlet of the membrane and therefore a thicker deposit layer. Based on the results of a sectioned membrane recent studies assume a thicker deposit layer at the inlet of the membrane due to a higher TMP and thus a lower permeation. However, the drawback so far is that all studies use indirect and off-line methods to measure the deposit layer. The actual thickness of the fouling layer during the filtration is not known. ${ }^{2}$ Complementary characterisation techniques are needed to gain more information about these spatially varying fouling phenomena.

Nuclear magnetic resonance imaging (MRI) is known to be a powerful technique for non-invasive observation of membrane processes. ${ }^{8-10}$ Recent examples for the application of MRI in membrane filtration research are the investigation of the fouling behaviour of spiral wound modules, the influence of feed spacers on the velocity distribution and biofouling of these modules. ${ }^{11-15} \mathrm{MRI}$ was also applied to measure flow, concentration polarization and cake layer formation in hollow fiber geometries..$^{8,16-19}$ Typically, colloidal particle suspensions ${ }^{16,20,21}$ or oil-water emulsions ${ }^{18,22}$ were used as model substances, exploiting the relaxation contrast in the images.

In this work the question is answered, whether a protein deposit layer on the membrane's surface can be detected based on different relaxation times of the retained substances and the feed medium. Therefore, the transverse and longitudinal relaxation were measured as a function of casein concentration, which is the main retained component during skim milk filtration. Based on these results, in situ $\mathrm{MRI}$ during a dead-end filtration was performed in order to detect the casein deposit layer on the membrane's inner surface.

\section{Material and methods In situ filtration set up}

The experiments were performed in a $200 \mathrm{MHz}$ MRI tomograph (Bruker Avance 200 SWB, Bruker BioSpin GmbH, Rheinstetten, Germany). Figure 1 shows the flow diagram of the in situ filtration set up.

The ceramic hollow fiber module is mounted into a ${ }^{1} \mathrm{H}$-NMR bird cage $(10 \mathrm{~mm}$ inner diameter) and installed in the tomograph. For the experiments the hollow fiber membrane is fixed in a glass module and connected via hose connections to the feed source and 


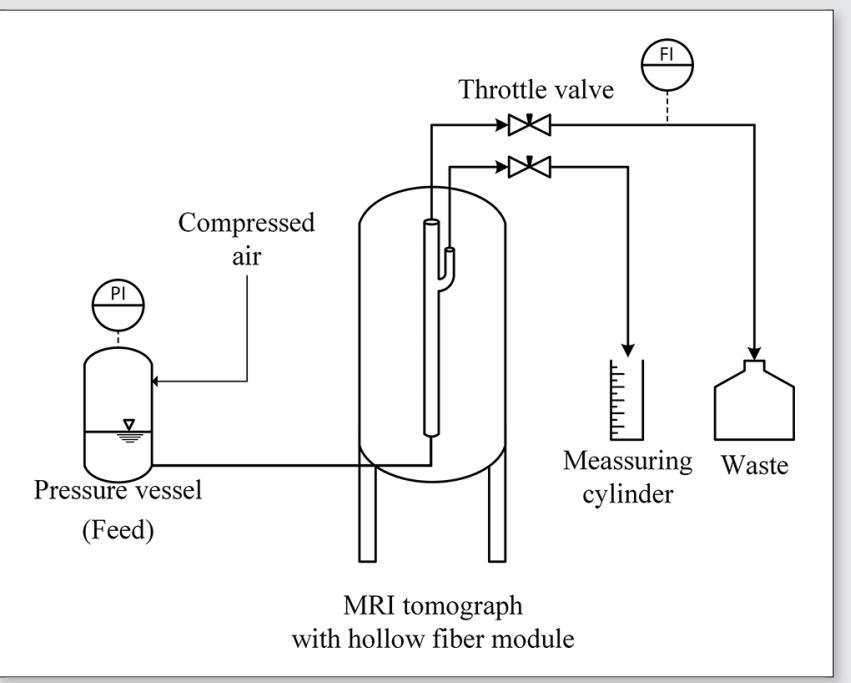

Figure 1. Flow diagram of the in situ filtration set up.

the collecting vessels. A pressure vessel is used for feed transport to avoid pulsation due to pumping and consequently to ensure an artefact-free measurement. Filtrations were performed with a constant transmembrane pressure of $100 \mathrm{kPa}$. Dead-end filtration rather than cross-flow filtration was chosen in order to realize a fast build-up of a deposit layer on the membrane's surface. The permeate was collected in a measuring cylinder volume to determine $V_{\text {Perm }}$ over time $t$. Knowing the active membrane area $A_{M e m}$, the permeate flux $J_{p}$ can be calculated according to:

$$
J_{P}=\frac{1}{A_{\text {Mem }}} \frac{d V_{\text {Perm }}}{d t}
$$

\section{Ceramic hollow fiber membranes}

Ceramic hollow fiber membranes were used due to their high chemical and thermal stability as well as high specific membrane surface. The ultrafiltration membranes have a nominal pore diameter of $40 \mathrm{~nm}$. They consist of $\alpha-\mathrm{Al}_{2} \mathrm{O}_{3}$ and have a radially asymmetric structure: A microporous support layer provides the mechanical stability, and a thin active layer on the membrane's feed facing surface determines the separation properties (Figure 1). Due to the localization of the active layer on the membrane's inner surface, the filtration mode is from the inside to the outside (in/out filtration). The membrane had an active filtration length of $445 \mathrm{~mm}$, an inner diameter of $1.74 \mathrm{~mm}$ and a clean water flux of $350 \mathrm{l} / \mathrm{m}^{2} / \mathrm{h}$ (measured at TMP of $100 \mathrm{kPa}$ ).

\section{Production of milk samples}

To avoid thermally induced interactions between serum proteins and casein micelles raw milk was collected directly from a local farm. The milk was separated with a pilot cream separator type MM $1254 \mathrm{D}$ (GEA Westfalia, Oelde, Germany) at 8,000 g and $50^{\circ} \mathrm{C}$ to obtain a skim milk with a fat content below $0.1 \%$. The skim milk was divided into two batches. The first batch was used for the deadend filtration directly whereas the second fraction was processed further to obtain a whey protein free casein concentrate. The casein micelles were fractionated from the whey proteins by means of microfiltration operated in diafiltration mode. It was coupled with an ultrafiltration membrane (cut off $10 \mathrm{kDa}$ ) according to Toro-Sierra etal. ${ }^{23}$ For microfiltration different conditions were used: It was operated in crossflow mode with ISOFLUX ${ }^{\circledR}$ membranes with a nominal cut-off of $0.14 \mu \mathrm{m}$ and a membrane area of $2.45 \mathrm{~m}^{2}$, consisting of seven ceramic modules in form of multichannel elements $1178 \mathrm{~mm}$ length, $3.5 \mathrm{~mm}$ diameter per channel, 23 channels, TAMI Industries, France). After concentrating the skim milk by a factor of two the same amount of milk and ideal whey (microfiltration permeate) were collected in the receiving tank of the microfiltration and ultrafiltration, respectively. Seven diafiltration steps were carried out at constant filling level by transferring the permeate of the ultrafiltration back to the receiving tank of the microfiltration to keep the natural milk milieu and avoid changes of the casein micelles. In this way, the whey protein concentration in the microfiltration retentate was reduced by $97.2 \%$. The final protein content of the casein concentrate was adjusted to $9.0 \%$ by concentration and spray dried (Spray Dryer B-290, Büchi, Switzerland) to a dry matter of 96.2\%. Casein suspensions were prepared by dissolving the proper amount of spray dried casein in ultra-pure water.

\section{$\boldsymbol{T}_{\mathbf{1}}$ and $\boldsymbol{T}_{\mathbf{2}}$ determination}

In order to measure $T_{1}$ and $T_{2}$ skim milk and the casein samples were filled into $5 \mathrm{~mm}$ NMR sample tubes and placed in the tomograph altogether. MSME with varying inversion times was applied to measure the magnetization recovery. During analysis of signal intensities $T_{1}$ relaxation times were determined by fitting an exponential growth function to the measured data points:

$$
\frac{M(t)}{M_{0}}=1-\exp \left(-\frac{t}{T_{1}}\right)
$$

$M(t)$ is the magnetization at time $t, M_{0}$ is the equilibrium magnetization and $T_{1}$ the longitudinal relaxation time. Transverse relaxation times $T_{2}$ were determined by measuring the samples in a multi echo sequence at different echo times $\left(t=n^{\star} \tau_{E}\right)$ at a fixed repetition time. $T_{2}$ was obtained using a fit of an exponential decay:

$$
\frac{M(t)}{M_{0}}=\exp \left(-\frac{t}{T_{2}}\right)
$$

\section{Results and discussion Influence of casein concentration on relaxation properties}

Figure 2a) displays the transverse relaxation times of casein suspensions with four different casein concentrations at two different repetition times. An increasing casein concentration leads to a faster signal decay of the transverse magnetization. As expected, the variation of $T R$ had no significant influence on $T_{2}$. Casein not only affects $T_{2}$ but also leads to a decrease of $T_{1}$. Casein causes the longitudinal and the transverse magnetization of the suspension to relax faster compared to the relaxation of pure water. These findings are in good agreement with the observations described in Ref. 24, 25. In the context of MRI during filtration processes of milk, this fact allows the exploration of relaxation contrast to detect the deposit layers formation.

\section{In situ MRI for observation of layer formation}

During dead-end filtration of skim milk, the retained feed fractions accumulate at the membrane and form a deposit layer. Due to the large mean diameter of casein micelles $\left(d_{50,3}=180 \mathrm{~nm}\right)$, they will be rejected by the hollow fiber membrane with a pore size of $40 \mathrm{~nm}$. 


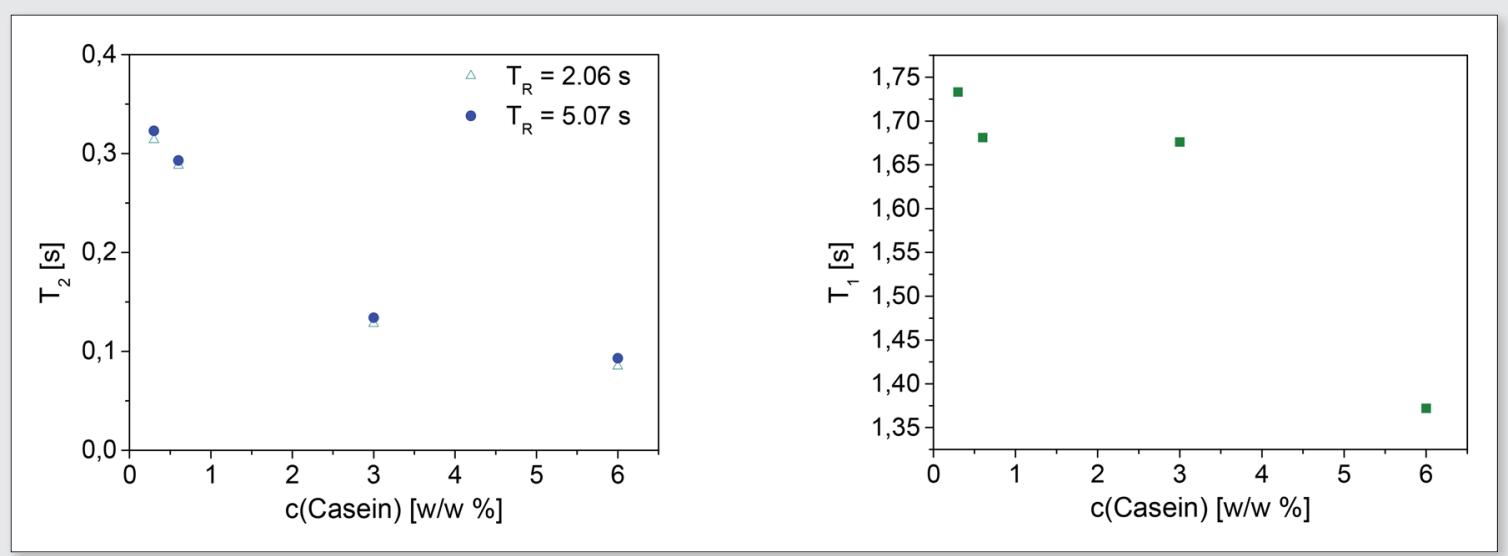

Figure 2. Both relaxation times $T_{2}$ and $T_{1}$ of a casein suspension depend on the casein concentration. The relaxation times decrease with increasing concentration and are therefore good measures for contrast generation in MRI.

The consequence is an accumulation of casein micelles in the deposit layer and hence a much higher concentration than in the skim milk feed solution. The effect on relaxation time in the region of the deposit layer is therefore even more pronounced as in the relaxation studies (Figure 2). When setting up an MRI experiment knowing that both relaxation times are influenced by the casein concentration, the contrast in the images has to be considered. A reduction of $T_{1}$ is equivalent with a signal enhancement, i.e. a positive contrast in $T_{1}$ weighted images, whereas a reduction in $T_{2}$ leads to a signal reduction, i.e. a negative contrast in echo based MRI sequences. Thus, with a shorter repetition time TR a stronger $T_{1}$ weighting can be achieved. Vice versa, an increase of the echo time leads to a more pronounced differentiation along $T_{2}$. An increase, a reduction or even an inversion of the image contrast can be obtained depending on the pulse sequence's timing. Good results were obtained at an average repetition time of $T R=800 \mathrm{~ms}$ and the minimum echo time (Figure 3) when applying Rapid Acquisition with Relaxation Enhancement (RARE) MRI. The inner circle in the axial image of the unfouled membrane (Figure 3a) represents the feed channel, followed by the membrane itself. The membrane shows a low intensity and therefore appears blue in the false colour images. This is not only due to the lower proton density in the membrane but also due to the short transverse relaxation times of molecules in the pores of the membrane. The observation of a brighter circle of higher intensity roughly in the middle of the membrane affirms this interpretation. This circle is caused by the water molecules located in the larger pores of the supporting layer (Figure 3f). The pore structure is not uniform over the cross section of the hollow fiber membrane. This is attributed to the production process and is in good agreement with the $\mu \mathrm{CT}$ image in Figure 3f). Furthermore, a quite thin ring with high intensities can be identified at the inner surface of the ceramic hollow fiber membrane prior to filtration (see Figure 3). This phenomenon could result from magnetic susceptibility differences of the ceramic hollow fiber and the surrounding skim milk ${ }^{26}$ but also from adsorption of proteins to the membrane surface.

During dead-end filtration of skim milk the deposit layer formation was measured as a function of time. In previous studies, RARE imaging has turned out to be feasible for time resolved and almost

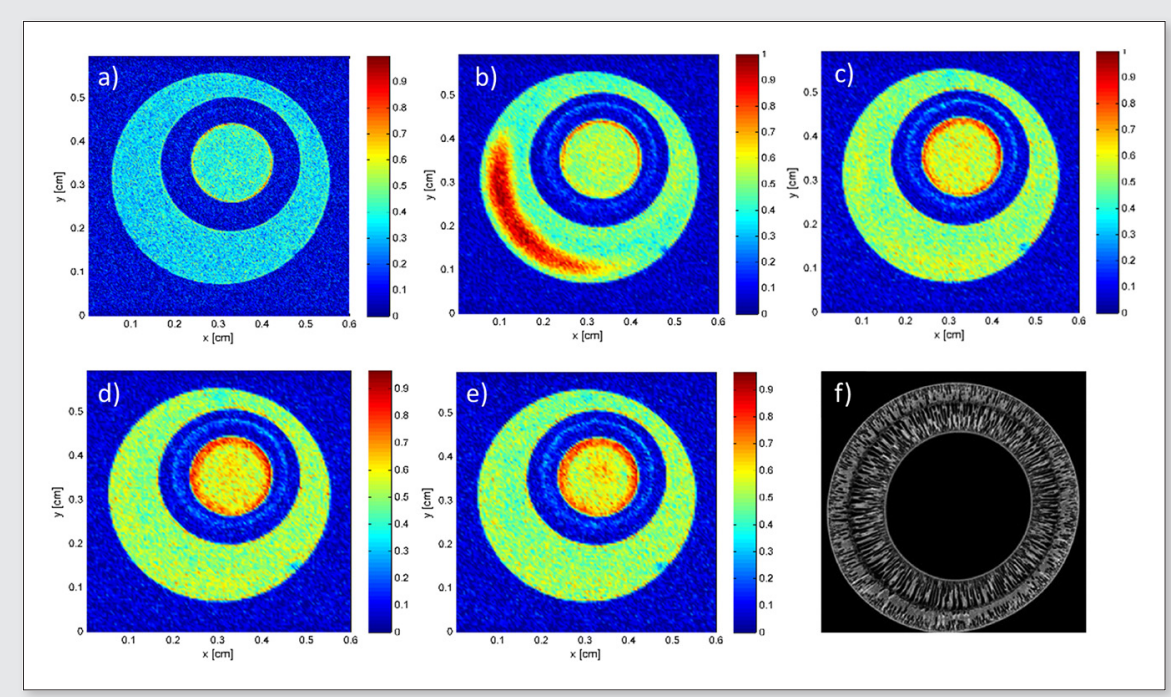

Figure 3. RARE-images of skimmed milk dead-end filtration at 1 bar TMP. a) before start, b) $7 \mathrm{~min}$, c) $27 \mathrm{~min}$, d) $39 \mathrm{~min}$, e) $46 \mathrm{~min}$ - Acquisition time: 2:08 min, $T_{\mathrm{R}}=800 \mathrm{~ms}, \tau_{\mathrm{E}}=3.709 \mathrm{~ms}$, FOV: $6 \times 6 \mathrm{~mm}$, Matrix: $128 \times 128$, RARE Factor: 8. Please note, that the images are individually scaled to the maximum intensity of each image, indicated by the corresponding colorbar. f) $\mu \mathrm{CT}$ image of a ceramic hollow fiber membrane. ${ }^{26,27}$ 
artefact free in situ monitoring of filtration. Five axial slices were measured, each having a thickness of $1 \mathrm{~mm}$. The results for the first of the five axial slices at different filtration times can be seen in Figure 3. With increasing filtration time, an area with high intensities is detected on the membrane's surface. This area corresponds to the formed deposit layer with increased concentration of $T_{1}$-shortening substances. Additionally, a region of high intensity in the lower left section of the image is recognizable (Figure 3b). This is likely due to flow artefacts resulting from the initial high flow in the permeate channel at the beginning of the filtration corresponding to the high filtration flux.

Furthermore it can be seen, that the deposit layer is not uniform. In the upper region of the membrane the deposit layer is much more pronounced than in the lower region. Simultaneously, the pore structure seems to be more open in the upper part of the membrane leading to a lower local membrane resistance. This in turn leads to a higher flow and hence more convective transport of casein micelles towards the membrane's surface resulting in a higher deposit layer.

The RARE images were quantitatively analysed as a function of filtration time. The thickness of the fouling layer was determined by a self-written MATLAB script, exploring the symmetry and the uniformity of the layer at the inner side of the hollow fiber membrane. Two ellipses, one describing the inner membrane's surface and one describing the interface of the fouling layer to the filtrate channel are defined interactively. The flexibility of this procedure takes the fabrication errors into account as well as the fact that an automated segmentation is difficult due to the varying image contrasts. Figure 4 displays the development of the deposit layer height as a function of filtration time.

The thickness of the deposit layer increases significantly at the beginning of the filtration process. This is due to the higher flux during in the beginning of dead-end filtration, which leads to a high convective transport of casein micelles to the membrane's surface. After this initial phase, the build-up of the deposit layer leads to an increased filtration resistance and therefore to a decrease of the filtration flux at constant pressure. The consequence is that the

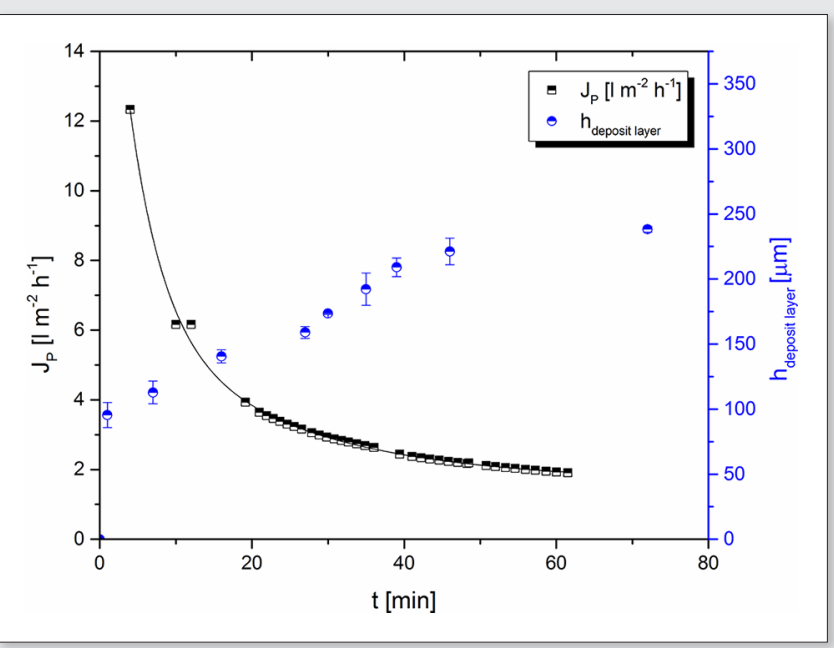

Figure 4. The flux $J_{p}$ decreases as a function of filtration time, where $J_{p}$ was measured integrally at the outlet of the module. In the same time, the height of the deposit layer increases as quantified from MRI images as shown in Figure 3. deposit layer increases and the filtration flux slows down. During dead-end filtration experiments it has to be considered, that not only casein micelles are rejected, but also whey proteins are partly embedded in the deposit layer, also leading to an alteration of $T_{1}$ and $T_{2}$ in this region. Regarding the extremely low values for the filtrate flux, it is worth to note, that on an industrial scale the fractionation of casein micelles and whey proteins is performed in crossflow filtration mode. The higher crossflow velocity leads to shear forces at the membrane's surface. These cause an at least partial removal of the deposit layer and therefore lead to a lower filtration resistance resulting in much higher filtrate fluxes. The removal of the deposit layer is very important, because the permeation of the whey proteins is reduced by the deposit layer, too. ${ }^{2}$ The objective of this article was to show that it is possible to measure the height of the fouling layer in-situ during the filtration of skim milk by means of MRI.

\section{Conclusion}

An increase of casein concentration results in a decrease of the transverse and longitudinal relaxation times of the aqueous suspension. Therefore it is possible to differentiate areas with high casein concentrations, e.g. in the fouling layer, from the feed solution with relaxation weighted MRI. The fouling layer was monitored time resolved during build up, and the thickness of the fouling layer was analysed as a function of duration of dead-end filtration of skim milk. Relaxation weighted MRI is shown to be a powerful tool to elucidate the underlying mechanism of length dependent deposit layer formation during the fractionation of skim milk and hence optimize filtration processes to avoid fouling. Further investigations will be performed regarding the application of MRI in cross flow filtration and the length dependence as well as the composition of the resulting deposit layer.

\section{Acknowledgement}

We would like to acknowledge the financial support of DFG for the instrumental facility Pro $^{2}$ NMR.

\section{References}

1. G. Daufin, J.P. Escudier, H. Carrere, S. Berot, L. Fillaudeau and M. Decloux, "Recent and Emerging Applications of Membrane Processes in the Food and Dairy Industry", Food and Bioproducts Processing 79, 89 (2001). doi: http://dx.doi.org/10.1205/096030801750286131

2. A. Piry, W. Kühnl, T. Grein, A. Tolkach, S. Ripperger and U. Kulozik, "Length Dependency of Flux and Protein Permeation in Crossflow Microfiltration of Skimmed Milk", Journal of Membrane Science 325, 887 (2008). doi: http://dx.doi.org/10.1016/j.memsci.2008.09.025

3. A.D. Marshall, P.A. Munro and G. Trägårdh, "The Effect of Protein Fouling in Microfiltration and Ultrafiltration on Permeate Flux, Protein Retention and Selectivity: A Literature Review", Desalination 91, 65 (1993). doi: http://dx.doi.org/10.1016/0011-9164(93)80047-Q

4. S. Nataraj, R. Schomäcker, M. Kraume, I.M. Mishra and A. Drews, "Analyses of Polysaccharide Fouling Mechanisms During Crossflow Membrane Filtration”, J. Membrane Sci. 308, 152 (2008). doi: http:// dx.doi.org/10.1016/i.memsci.2007.09.060

5. T. Melin and R. Rautenbach, Membranverfahren: Grundlagen Der Modul- Und Anlagenauslegung. Springer Berlin Heidelberg, (2013).

6. W.J.C. van de Ven, K.v.t. Sant, I.G.M. Pünt, A. Zwijnenburg, A.J.B. Kemperman, W.G.J. van der Meer and M. Wessling, "Hollow Fiber Dead-End Ultrafiltration: Influence of lonic Environment on Filtration of Alginates", J. 
Membrane Sci. 308, 218 (2008). doi: http://dx.doi.org/10.1016/.memsci.2007.09.062

7. C. Gernedel, Über Die Ultrafiltration Von Milch Und Die Den Widerstand Der Ablagerungsschicht Beeinflussenden Faktoren. Technische Universität München (1980).

8. S. Bütehorn, Experimental and Numerical Investigation of the Hydrodynamics of Microfiltration Processes Using a Multi-Scale Approach Rheinisch-Westfälischen Technischen Hochschule Aachen (2011).

9. J.C. Chen, Q. Li and M. Elimelech, "In Situ Monitoring Techniques for Concentration Polarization and Fouling Phenomena in Membrane Filtration", Adv. Colloid Interfac. 107, 83 (2004). doi: http://dx.doi. org/10.1016/j.cis.2003.10.018

10. V. Chen, H. Li and A.G. Fane, "Non-Invasive Observation of Synthetic Membrane Processes - a Review of Methods", Journal of Membrane Science 241, 23 (2004). doi: http://dx.doi.org/10.1016/j.memsci.2004.04.029

11. J.S. Vrouwenvelder, D.A. Graf von der Schulenburg, J.C. Kruithof, M.L. Johns and M.C.M. van Loosdrecht, "Biofouling of Spiral-Wound Nanofiltration and Reverse Osmosis Membranes: A Feed Spacer Problem", Water Research 43, 583 (2009). doi: http://dx.doi.org/10.1016/1. watres.2008.11.019

12. J.S. Vrouwenvelder, C. Hinrichs, W.G.J. Van der Meer, M.C.M. Van Loosdrecht and J.C. Kruithof, "Pressure Drop Increase by Biofilm Accumulation in Spiral Wound Ro and Nf Membrane Systems: Role of Substrate Concentration, Flow Velocity, Substrate Load and Flow Direction", Biofouling 25, 543 (2009). doi: http://dx.doi.org/10.1080/08927010902972225

13. J.S. Vrouwenvelder, C. Picioreanu, J.C. Kruithof and M.C.M. van Loosdrecht, "Biofouling in Spiral Wound Membrane Systems: ThreeDimensional CFD Model Based Evaluation of Experimental Data", J. Membrane Sci. 346, 71 (2010). doi: http://dx.doi.org/10.1016/j.memsci.2009.09.025

14. S.A. Creber, T.R.R. Pintelon, D.A.W. Graf von der Schulenburg, J.S. Vrouwenvelder, M.C.M. van Loosdrecht and M.L. Johns, "Magnetic Resonance Imaging and 3d Simulation Studies of Biofilm Accumulation and Cleaning on Reverse Osmosis Membranes", Food and Bioproducts Processing 88, 401 (2010). doi: http://dx.doi.org/10.1016/j. fbp.2010.08.010

15.D.A. Graf von der Schulenburg, J.S. Vrouwenvelder, S.A. Creber, M.C.M. van Loosdrecht and M.L. Johns, "Nuclear Magnetic Resonance Microscopy Studies of Membrane Biofouling", Journal of Membrane Science 323, 37 (2008). doi: http://dx.doi.org/10.1016/i.memsci.2008.06.012

16. D. Airey, S. Yao, J. Wu, V. Chen, A.G. Fane and J.M. Pope, "An Investigation of Concentration Polarization Phenomena in Membrane Filtration of Colloidal Silica Suspensions by Nmr Micro-Imaging", J. Membrane Sci. 145, 145 (1998). doi: http://dx.doi.org/10.1016/S03767388(98)00051-9
17. C.A. Heath, G. Belfort, B.E. Hammer, S.D. Mirer and J.M. Pimbley, "Magnetic Resonance Imaging and Modeling of Flow in Hollow-Fiber Bioreactors", Aiche J 36, 547 (1990). doi: http://dx.doi.org/10.1002/ aic.690360406

18. J.M. Pope, S. Yao and A.G. Fane, "Quantitative Measurements of the Concentration Polarisation Layer Thickness in Membrane Filtration of Oil-Water Emulsions Using NMR Micro-Imaging", J. Membrane Sci. 118, 247 (1996). doi: http://dx.doi.org/10.1016/0376-7388(96)00107-X

19. S. Laukemper-Ostendorf, H.D. Lemke, P. Blümler and B. Blümich, "NMR Imaging of Flow in Hollow Fiber Hemodialyzers", J. Membrane Sci. 138, 287 (1998). doi: http://dx.doi.org/10.1016/S0376-7388(97)00241-X

20. S. Bütehorn, L. Utiu, M. Küppers, B. Blümich, T. Wintgens, M. Wessling and T. Melin, "NMR Imaging of Local Cumulative Permeate Flux and Local Cake Growth in Submerged Microfiltration Processes", Journal of Membrane Science 371, 52 (2011). doi: http://dx.doi.org/10.1016/j. memsci.2011.01.018

21. P.Z. Çulfaz, S. Buetehorn, L. Utiu, M. Kueppers, B. Bluemich, T. Melin, M. Wessling and R.G.H. Lammertink, "Fouling Behavior of Microstructured Hollow Fiber Membranes in Dead-End Filtrations: Critical Flux Determination and NMR Imaging of Particle Deposition", Langmuir 27, 1643 (2011). doi: http://dx.doi.org/10.1021/la1037734

22. S. Yao, M. Costello, A.G. Fane and J.M. Pope, "Non-Invasive Observation of Flow Profiles and Polarisation Layers in Hollow Fibre Membrane Filtration Modules Using NMR Micro-Imaging", J. Membrane Sci. 99, 207 (1995). doi: http://dx.doi.org/10.1016/0376-7388(94)00219-O

23. J. Toro-Sierra, A. Tolkach and U. Kulozik, "Fractionation of A-Lactalbumin and B-Lactoglobulin from Whey Protein Isolate Using Selective Thermal Aggregation, an Optimized Membrane Separation Procedure and Resolubilization Techniques at Pilot Plant Scale", Food and Bioprocess Technology 6, 1032 (2013). doi: http://dx.doi.org/10.1007/ s11947-011-0732-2

24. S. Salami, C. Rondeau-Mouro, J. van Duynhoven and F. Mariette, "Probe Mobility in Native Phosphocaseinate Suspensions and in a Concentrated Rennet Gel: Effects of Probe Flexibility and Size", J. Agr. Food Chem. 61, 5870 (2013). doi: http://dx.doi.org/10.1021/Jf304949c

25. G.V. Alekseev and A.A. Khripov, "Method of Rapid Remote Control of Casein Concentration in Dairy Products in Unopened Packages", J Food Process Eng 38, 11 (2015). doi: http://dx.doi.org/10.1111/ifpe.12121

26. F. Arndt, U. Roth, H. Nirschl, S. Schütz and G. Guthausen, "New Insights into Sodium Alginate Fouling of Ceramic Hollow Fiber Membranes by Nmr Imaging", Aiche J 62, 2459 (2016). doi: http://dx.doi.org/10.1002/ aic. 15226

27. D. Groß, K. Zick and G. Guthausen "Recent MRI and Diffusion Studies of Food Structures", in Annu. Rep. NMR Spectr., Ed by G.A. Webb. Elsevier, Academic Press, in press (2016). 